\title{
Quality Evaluation of Tertiary Treatment Effluent in Jahra Sewage Plant, Kuwait
}

\author{
Saud B. Al-Shammari \\ Environmental Health Departments, College of Health Science, The Public Authority for Applied Education and Training, P.O. Box \\ 14281, Faiha 72853, Kuwait
}

\begin{abstract}
Wastewater is being increasingly recognized as an important element in water management in Kuwait, where freshwater is limited and scarce. Currently, huge amount of municipal wastewater in Kuwait receives conventional treatment up to tertiary level. This study evaluates and analyzes the performance and the tertiary treatment process in Jahra sewage plant. The performance evaluation was done based on removal efficiency of BOD (biochemical oxygen demand), TSS (total suspended solids), TN (total nitrogen) and TP (total phosphorus). The results indicated that a significant reduction in TSS, BOD, was observed in tertiary effluent. The results show that the average removal efficiencies of the system for TSS and BOD, were $89 \%$ and $66 \%$ respectively. However, poor reduction in phosphate and nitrogen contents was noticed with average removal of $6 \%$ and $7 \%$ respectively. The tertiary effluent satisfied the water quality guidelines and standards applied in Kuwait for restricted irrigation.
\end{abstract}

Key words: Sand filtration, wastewater, treatment, reuse.

\section{Introduction}

Kuwait is an arid country with absence of fresh surface water, limited rainfall, and depleted groundwater resources. In recent years, treatment of wastewater in Kuwait has become essential not only for environmental protection of aquatic ecosystem but also for augmenting limited water resources by reusing of treated wastewater [1]. This resource could be efficiently treated at a reasonable cost and, thereafter, reused in irrigation and landscaping. This issue is crucial to Kuwait, since water demands for agricultural, industrial and domestic uses have grown in the past few years. This would eliminate excessive production of brackish water and conserve Kuwait's groundwater aquifers. The collected sewage in Kuwait is treated in four main wastewater treatment systems located at Um-Alhaiman, Sulaibiya, Riqqa and Jahra.

In general, sewage treatment in Kuwait is accomplished through three stages: primary,

Corresponding author: Saud B. Al-Shammari, Ph.D., associate professor, research fields: water and wastewater treatment, environmental engineering and seawater desalination. secondary, and tertiary. In the primary treatment, i.e., physical treatment, wastewater is first received at the headwork building for treatment, where floatables and debris are removed using bar screens and grit sedimentation. Secondary treatment, i.e., biological treatment, is the main treatment stage, different types of activated sludge treatment processes are used such as extended aeration process. In the tertiary treatment, i.e., disinfection and filtration, secondary treated effluent is first subjected to disinfection by chlorine before being collected in two balancing tanks. The water is then transferred to a filtration plant, where sand filters separate the remaining fine suspended solids from the water before final disinfection.

The aim of this study is to evaluate the treatment efficiency and the effluent quality of the extended aeration sludge system in Jahra wastewater treatment plant.

\section{Jahra Wastewater Treatment Plant}

The Jahra sewage plant is located at the northwest of Kuwait City and adjacent to Jahra satellite town. It started operation in 1983 with an average design 
capacity of $86,000 \mathrm{~m}^{3} / \mathrm{d}$. Present inflow is $65,000 \mathrm{~m}^{3} / \mathrm{d}$. The plant consists of EASP (extended-aeration sludge process) with clarifier, and tertiary treatment. As it has no primary clarifiers, raw wastewater flows directly from the preliminary treatment (coarse screening and grit removal) level to EASP units and then to the tertiary treatment units. The sludge is wasted from the aeration basins and thickened in a sludge thickener before spreading thickened sludge on drying beds. Dried sludge is removed from the plant by truck loads.

It provides treatment up to tertiary level with sand filtration and disinfection at the final stages. The bulk of the effluent of the plant is sent to central reservoir of irrigation water supply at, Data Monitoring Centre (MPW). Part of the effluent is used by site irrigation and tanker supply to irrigation sites. A small portion of the effluent is occasionally discharged to sea. Fig. 1 demonstrates flow diagram of tertiary wastewater treatment stage, which consisted of disinfection and filtration. No chemicals (coagulant or coagulant aid) are added prior to the filtration and therefore coagulation/flocculation process is omitted in Jahra wastewater treatment plant. Filtration is conducted through gravity rapid sand filter, which consists of a $60 \mathrm{~cm}$ sand layer overlaying a $40 \mathrm{~cm}$ gravel layer acting as support media. The design filtration rate is 5 $\mathrm{m}^{3} / \mathrm{m}^{2}$.hr. The media filter is backwashed daily for 15 min with compressed air and pressurized water. Disinfection by chlorine gas is conducted before and after sand filtration. Prechlorination is used to kill algae responsible for filter biofouling whereas post chlorination is used to ensure total disinfection of the final effluent [2].

\section{Materials and Methods}

\subsection{Monitoring Jahra Plant}

Data collected for this work were part of comprehensive evaluation study of Jahra wastewater

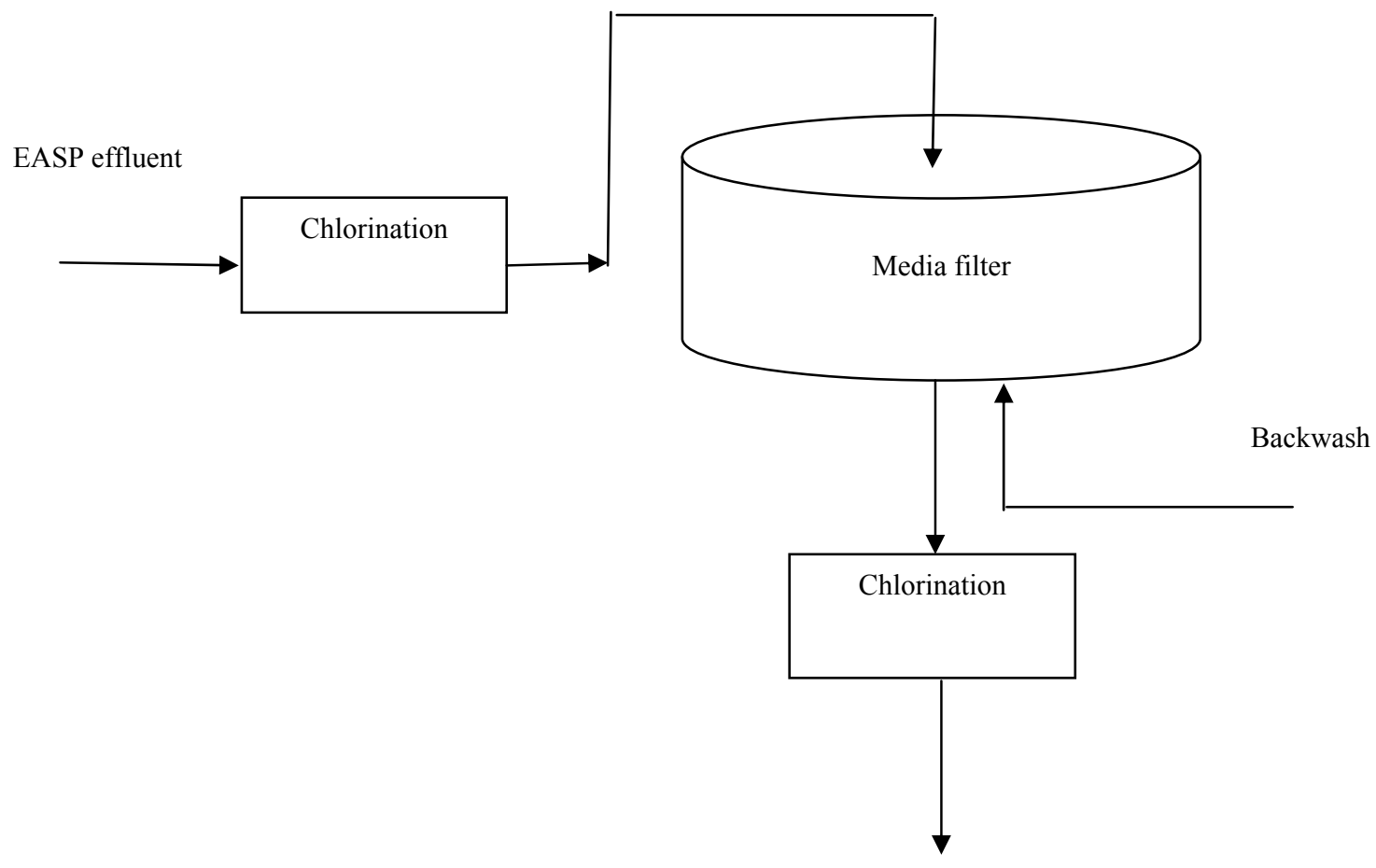

Effluent

Fig. 1 Process flow diagram of tertiary treatment stage. 
treatment plant in which samples were collected in two distinct groups:

- Weekly samples from unit processes

- Extensive-day monitoring

Samples were collected once in each week from designated locations for 12 months starting from May 2004 to ending in April, 2005. The sampling locations were selected with a purpose of determination of performances of tertiary treatment stage and the quality of tertiary treated effluent. The sample points were:

- Clarifier effluent

- Sand filter effluent

All analysis in the laboratory was performed according to the Standard Methods [3]. The purpose of these long-term data collection at regular week interval was to observe average trend and unusual variations in inflow and unit performances through a year-long period.

\subsection{Sample Analysis}

All samples were analyzed at WRP laboratory at Sulaibiya according to standard methods. Jahra plant inflow records were adopted directly from the plant flow records. In addition, several parameters such as $\mathrm{BOD}_{5}$ (biochemical oxygen demand), COD (chemical oxygen demand), oil and grease, and TSS (total suspended solids) were determined at Jahra plant laboratory.

\section{Results and Discussion}

\subsection{Efficiency of Tertiary Treatment Stage}

A statistical analysis of data collected from secondary and tertiary effluent lines was conducted to investigate the efficiency of tertiary treatment process in Jahra wastewater treatment plant. Table 1 summarizes the measurement and results obtained during this investigation. The tested parameters were limited to TSS, BOD, TN, and TP. In addition, coliform and fecal coliform measurements were also conducted to tertiary effluent to evaluate the efficiency of chlorination process. The analysis includes maximum, minimum, mean average and standard deviation values. Reported results show that the characteristics of the secondary treated wastewater were significantly improved, and an effluent of good quality was produced.

Figs. 2 and 3 show a graphical representation of the TSS and BOD values of the tertiary effluent compared with those of the secondary effluent whereas Fig. 4 demonstrates the distribution of percent removal of tested parameters. As shown in Fig. 2 the TSS of the filtrate ranged between 2.7 and $10.3 \mathrm{mg} / \mathrm{L}$, with a mean value of $3.8 \mathrm{mg} / \mathrm{L}$. Fig. 3 depicts BOD measurements of secondary effluent and tertiary filtrate. Most of the BOD values of the filtrate were less than $18 \mathrm{mg} / \mathrm{L}$, with an average value of 10.19 $\mathrm{mg} / \mathrm{L}$. The effectiveness of the tertiary treatment process in producing very good quality effluent by rejecting suspended solids and organic load is clear. Fig. 4 shows that the TSS average removal is almost $90 \%$ whereas the average removal of BOD is $66 \%$, which is considered as a significant reduction. These removal efficiencies are similar to that reported by several researchers that investigated media filtration in the literature $[4,5]$.

Table 1 Analysis of secondary and tertiary effluents.

\begin{tabular}{lllllllll}
\hline \multirow{2}{*}{ Parameters } & \multicolumn{3}{c}{ Secondary effluent } & \multicolumn{5}{c}{ Tertiary effluent } \\
\cline { 2 - 9 } & Max & Min & Ave & Std & Max & Min & Ave & Std \\
\hline TSS (mg/L) & 33.7 & 17.7 & 23 & 5.45 & 10.3 & 2.7 & 4.01 & 2.17 \\
BOD (mg/L) & 33.5 & 19.5 & 25.6 & 5.1 & 17.2 & 3.5 & 10.19 & 4.27 \\
VSS (mg/L) & 23.3 & 13.6 & 17.95 & 3.24 & 18 & 0.5 & 3 & 3.5 \\
TN (mg/L) & 27 & 10.20 & 16.25 & 4.89 & 26.2 & 7.6 & 15.79 & 5.6 \\
TP (mg/L) & 22.10 & 6.90 & 13.65 & 4.98 & 33 & 12.5 & 12.9 & 7.3 \\
\hline
\end{tabular}




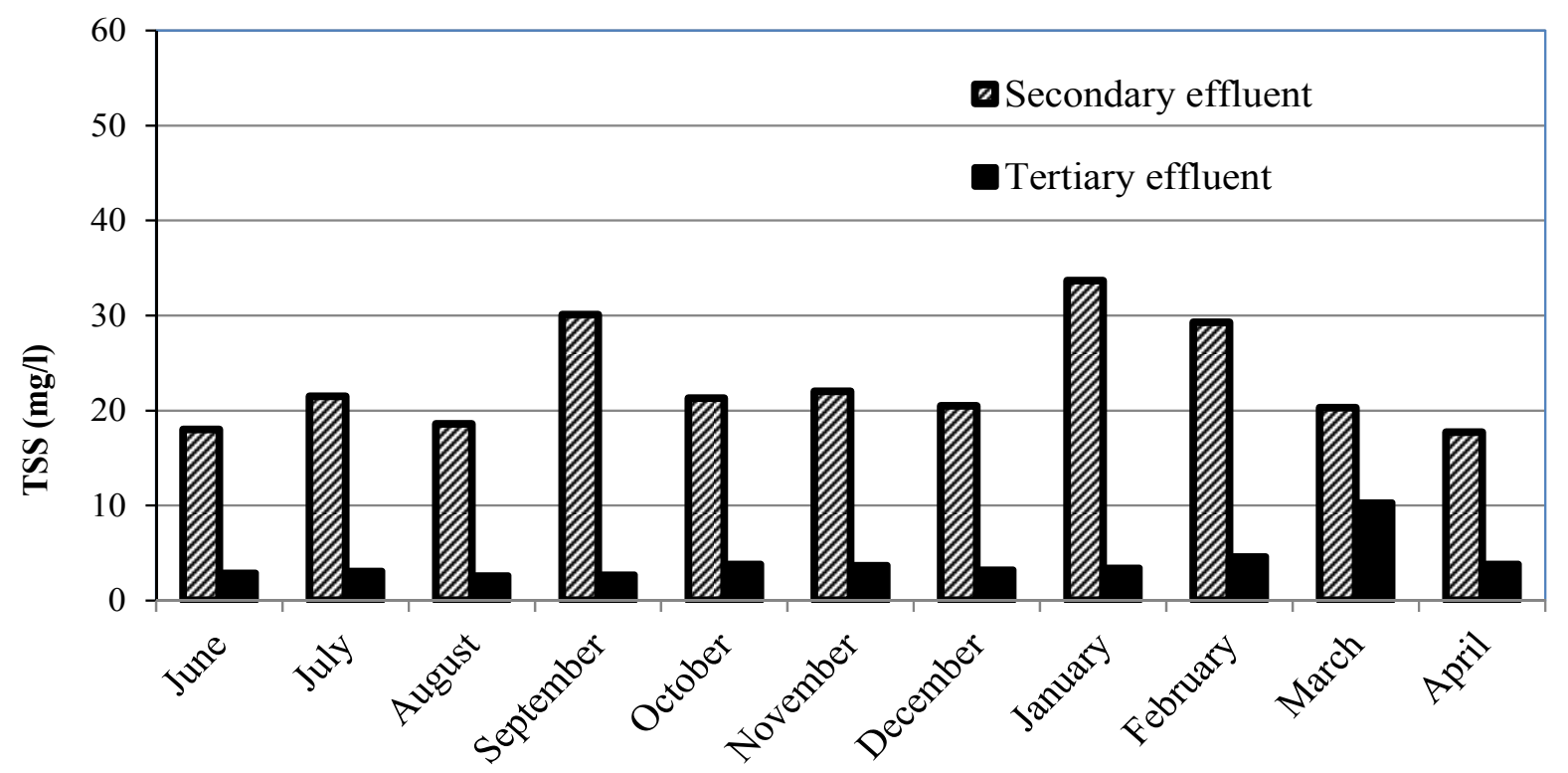

Fig. 2 Monthly variation of TSS in secondary and tertiary treated effluent.

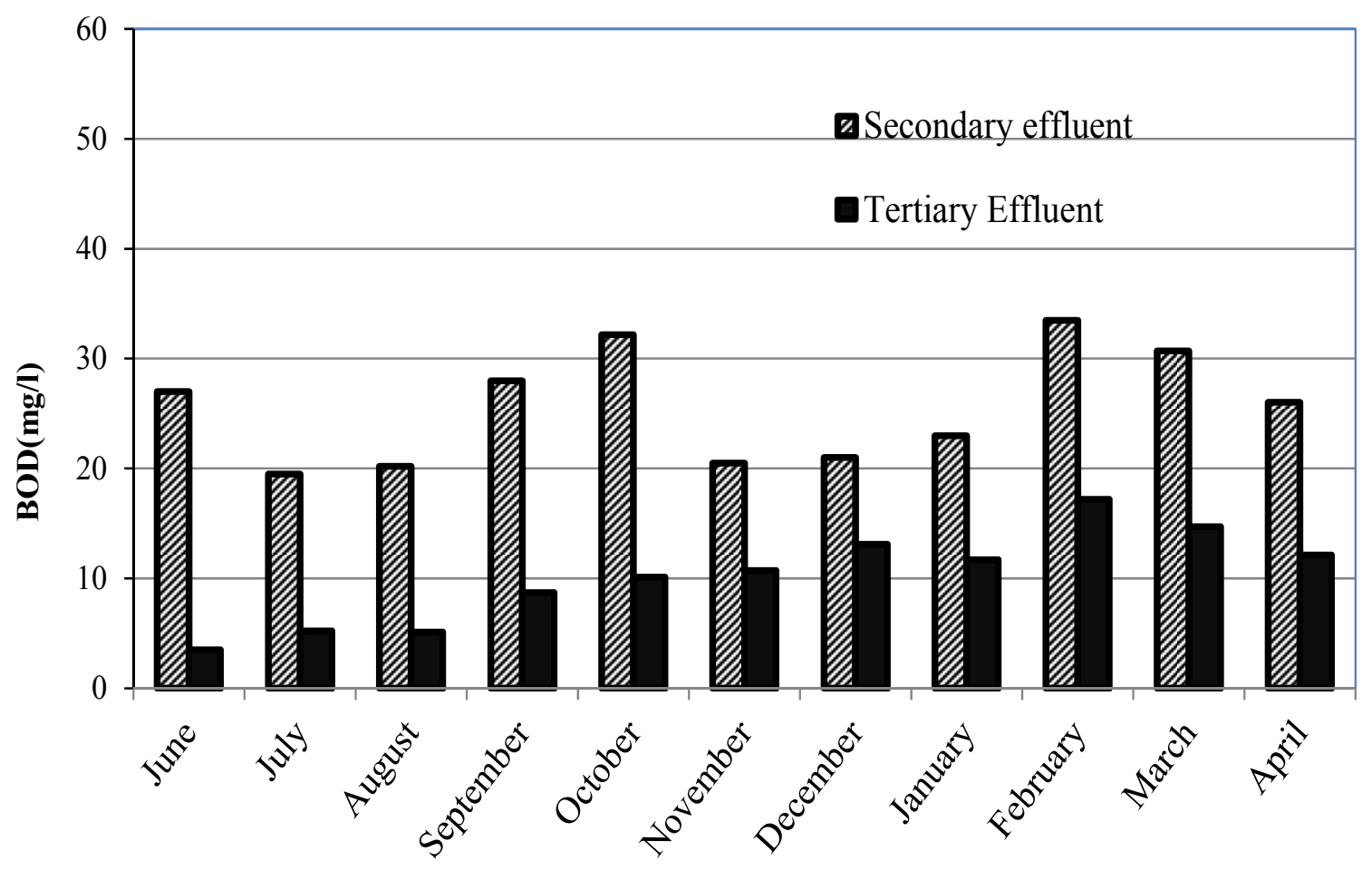

Fig. 3 Monthly variation of BOD in secondary and tertiary treated effluent. 


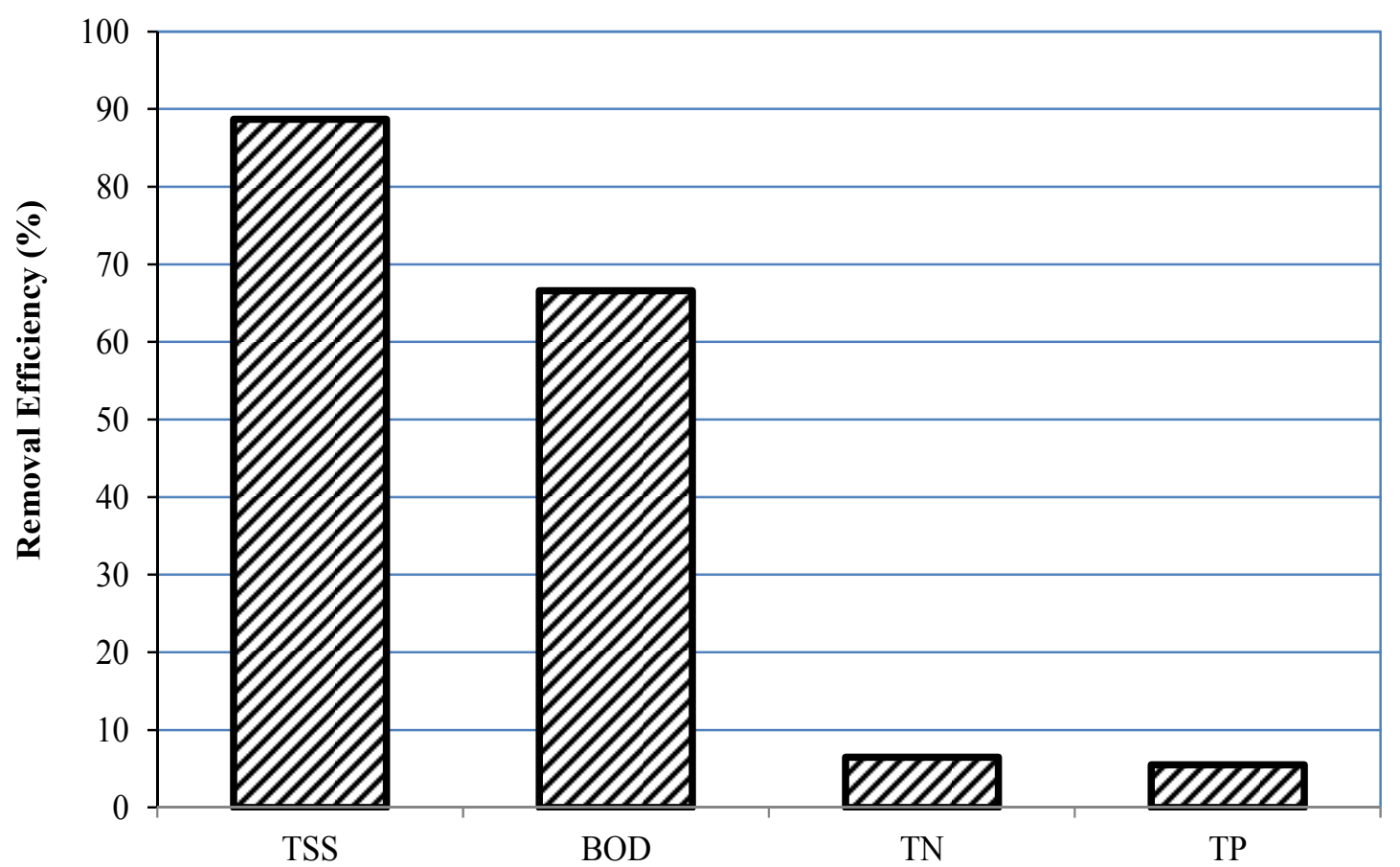

Fig. 4 Removal efficiency of tested parameters of tertiary treatment.

Table 2 Comparison of tertiary treated effluent to standards of KEPA and MPW guidelines for wastewater reuse in landscape irrigation in Kuwait (Source[7, 8]).

\begin{tabular}{llll}
\hline Parameter & Tertiary effluent & EPA Standards & MPW Standards \\
\hline $\mathrm{pH}$ & 7.5 & $6.5-8.5$ & 7.6 \\
$\mathrm{BOD}_{5}(\mathrm{mg} / \mathrm{L})$ & 10 & 20 & 3 \\
$\mathrm{COD}(\mathrm{mg} / \mathrm{L})$ & - & 100 & 54 \\
$\mathrm{TSS}(\mathrm{mg} / \mathrm{L})$ & 4 & 15 & 8 \\
$\mathrm{TP}(\mathrm{mg} / \mathrm{L})$ & 12 & 30 & 17.3 \\
$\mathrm{TN}(\mathrm{mg} / \mathrm{L})$ & 15 & 15 & 18.4 \\
Coliform $($ colony $/ 100 \mathrm{~mL})$ & 2.3 & 400 & 11 \\
Fecal coliform $($ colony $/ 100 \mathrm{~mL})$ & 1 & 20 & 8 \\
\hline
\end{tabular}

The average $\mathrm{TN}$ and $\mathrm{TP}$ values of the filtrate as presented in Table 1 are 15.79 and $12.5 \mathrm{mg} / \mathrm{L}$, respectively. High TN content in secondary effluent is expected since Jahra sewage plant has only oxic tanks and is not equipped with anoxic tanks. Thus, it is not designed for enhanced nitrogen removals. Only nitrification processes are expected to take place in the aeration tanks and very little chance for denitrification process to take place in the oxic tank. Nitrification processes only convert ammonia to nitrates but do not remove nitrogen from wastewater. Thus, in conventional sewage plants with no anoxic tank such as Jahra plants, $\mathrm{TN}$ removal in secondary stage is expected to be in the range of 50-60\% [6]. However, nitrogen removal process is unlikely to take place in tertiary treatment stage and therefore TN concentration in secondary and tertiary effluents is almost the same and no significant reduction occurs. Phosphorus removal is also very limited in tertiary treatment process since there are no chemicals such as ferric chloride or alum which were added before filtration process. Therefore, low average removal efficiencies of $\mathrm{TN}(7 \%)$ and $\mathrm{TP}(6 \%)$ were noticed and shown in Fig. 4. Biological analysis of tertiary filtrate showed that the prechlorination and chlorination processes are very effective in 
eliminating the coliform and fecal coliform with average values of 2.3 and 1 (colonies/100 mL) respectively.

\subsection{Treated Effluent Quality and Quality Standards for Water Reuse in Kuwait}

In recent years, the use of tertiary treated wastewater for landscape irrigation in an urban environment has gained more attention. However, there are serious concerns regarding health risk caused by pathogens [2]. Therefore, treated wastewater effluent reuse is subjected to stringent standards and guidelines to eliminate this risk. In Kuwait, there are two numerical sets of standards for the quality of treated wastewater effluent, which can be used for landscape irrigation. The first set of standards was issued by the MPW (Ministry of Public Work), while the second one was proposed by the KEPA (Kuwait Environmental Public Authority) [9]. The MPW standard is intended for regulating the operation of the municipal plants; and thus, only municipal plants operators use it. KEPA set of standards was proposed for regulating the quality of treated wastewater used as irrigation water in Kuwait. Table $2[7,8]$ compares these two sets of standards with tertiary treated effluent discharged from Jahra sewage plant. As can be seen from this table, numerical values of the MPW standards are generally stricter than the KEPA standards. Since currently treated wastewater is used for irrigating only fodder crops and landscapes, the quality required even by KEPA standards is more than adequate. Table 2 also clearly shows that the tertiary treated effluent from Jahra sewage plant is generally of a very high quality and the chemical and biological characteristics of the effluent confirm its suitability for irrigation purposes because the entire relevant values lie within the permissible limits established by KEPA. In fact, tertiary effluents of Jahra sewage plant receive more than the adequate treatment required for irrigation and agricultural reuse.

\section{Conclusion}

The study showed that tertiary treatment stage is essential in improving secondary effluent quality and the results have shown significant reduction in chemical and biological parameters. In addition, the tertiary treated effluents from Jahra sewage plant satisfy national requirements and guidelines for restricted irrigation. Consequently this will augment and preserve the limited water resources in Kuwait.

\section{Acknowledgments}

The authors would like to thank Kuwait Institute for Scientific Research for funding the study. Data used in this study were collected during the execution of a project entitled "Monitoring and Performance Evaluation of an Activated Sludge Process Treating Municipal Wastewater in Kuwait-A Case Study".

\section{References}

[1] Al-Anzi, B., Abusam, A., and Shahalam, A. 2012. "Assessment of Wastewater Reuse in Kuwait and Its Impact on Amount of Pollutants Discharged into the Sea." Journal of Environmental Protection 3: 935-9.

[2] Hamoda, M. F., Al-Ghusain, I., and Al-Mutairi, N. Z. 2004. "Sand Filtraion of Wastewater for Tertiary Treatment and Water Reuse." Desalination 164: 203-11.

[3] APHA. 2005. Standard Methods for the Examination of Water and Wastewater (21st ed.). Washington: American Public Health Association.

[4] Metcalf and Eddy, Inc. 2003. Wastewater Engineering: Treatment and Reuse (4th ed.). New York: McGraw-Hill.

[5] Kirkpatrick, W. P., and Asano, T. 1986. "Evaluation of Tertiary Treatment System for Wastewater Reclamation and Reuse." Water Science Technology 10: 83-95.

[6] Fang, H. H. P., Yeong, C. L. Y., Book, K. M., and Chiu, C. M. 1993. "Removal of COD and Nitrogen in Wastewater Using Sequencing Batch Reactor with Fibrous Packing." Water Science Technology 28 (7): 125-31.

[7] Parsons Engineering Science Inc. and Gulf Consult. 2001. Kuwait Sewerage Improvements Phase VIII/Part A and Other Works (Kuwait Treated Effluent Utilization Master Plan) Preliminary Report. Ministry of Public Works (MPW), Kuwait. 
[8] Kuwait Environmental Public Authority (KEPA). 2001 Kuwait Al-Youm (Today) Newspaper, Annex to Issue 533, Year 47.

[9] Al-Shammari, S. B., Al-Khalaf, B., Al-Sharafi, F., and
Shahalam, A. M. 2013. "Quality Assessment of Treated Wastewater in Kuwait and Possibility of Reuse It to Meet Growing Water Demand." Desalination and Water Treatment 51: 4497-505. 